\title{
Linhas Serpentinas: \\ Notas sobre uma abordagem labaniana do espaço
}

\author{
Paulo Caldas ${ }^{1}$ \\ Universidade Federal do Ceará - UFC, Fortaleza/CE, Brasil \\ E-mail: paulocaldasmail@gmail.com
}

\section{Resumo}

Abstract

A partir da afirmação de uma concepção dinâmica do espaço e do reconhecimento da linha como seu elemento generativo recorrente, o ensaio aborda concepções de Rudolf Laban e seus prolongamentos nos processos investigativos de William Forsythe.

\section{Palavras-chave}

Rudolf Laban. William Forsythe. Coreografia. Espaço. Linha.
Based on the assertion of a dynamic conception of space and the recognition of the line as its recurring generative element, the paper addresses Rudolf Laban's conceptions and their extensions in William Forsythe's investigative processes.

\section{Keywords}

Rudolf Laban. William Forsythe. Choreography. Space. Line. 


\section{O espaço dinâmico}

Na epígrafe de um ensaio do geógrafo Jean-Marc Besse (2007, p. 11, tradução nossa), lemos: "É chegado o momento de tomar consciência da natureza fluida do espaço". A frase é de Rudolf Laban, com quem assume compartilhar "[...] da perspectiva de um espaço que não preexiste ao caminho e, mais genericamente, ao movimento, mas que, ao contrário, é produzido, tanto no plano da realidade efetiva quanto no plano da percepção, pelos percursos".

O espaço se concebe aí, portanto, não como um receptáculo, um fundo passivo, indiferenciado e anterior, uma instância inerte onde se dá a dinâmica dos corpos, mas como, ele mesmo, dinâmico. Neste sentido, tal concepção generativa o faz necessariamente plural: diríamos então, de preferência, espaços, espécies de espaços ${ }^{2}$, produzidos distintamente segundo regimes e matrizes experienciais variáveis.

É fato que sempre é possível haver, num projeto coreográfico, uma primeira compreensão do espaço como o local, o cenário em que um acontecimento se dá: teatral ou não, urbano ou não, interior ou exterior, não importa, nela o espaço é tomado como preenchível e ocupável; mas há uma outra compreensão - que diríamos ser, aliás, eminentemente coreográfica - que reconhece o espaço como uma dimensão construtiva e escultórica dos acontecimentos. Nela, o espaço é "dinâmico"3, pois composto performativamente pelos corpos em suas configurações e ações, feitas de vetores, tensões, distensões, detenções e velocidades variáveis.

1 Paulo Caldas é coreógrafo e professor dos cursos de Bacharelado e Licenciatura em Dança no Instituto de Cultura e Arte da UFC.

2 Referência à obra de Georges Perec, publicada em 1974: Espèces d'espaces.

3 Referência ao título de um ensaio de Laban (L'espace dynamique - le sixième sens), utilizado também para nomear a coletânea de escritos labanianos publicada em francês, em 2003, com textos inéditos, Choreutique e Vision de l'espace dynamique, traduzidos por Élisabeth Schwartz-Remy (ver LABAN, 2003).
É recorrente acompanhar tal distinção em Michel de Certeau, nos termos em que a opera, que nomeia como "lugar" aquele que é ocupável, e como "espaço" - propriamente - aquele que é performado:

Um lugar é a ordem (seja qual for) segundo a qual se distribuem elementos nas relações de coexistência. [...] Um lugar é [...] uma configuração instantânea de posições. Implica uma indicação de estabilidade. [...] Existe espaço sempre que se tomam em conta vetores de direção, quantidades de velocidades e a variável tempo. [...] Espaço é o efeito produzido pelas operações que o orientam, o circunstanciam, o temporalizam [...]. Em suma: o espaço é um lugar praticado. (CERTEAU, 1998, p. 201-202, grifos nossos).

Desde a afirmação de que "[... ] a rua geometricamente definida por um urbanismo é transformada em espaço pelos pedestres", é o próprio Certeau (1998, p. 202) que nos reenvia para Maurice Merleau-Ponty e sua distinção entre o espaço geométrico e o espaço antropológico. Mas, além do espaço, em Certeau, do espaço antropológico, em Merleau-Ponty e do que ele mesmo se refere como espaço-de-paisagem (espace-du-paysage), Jean-Marc Besse (2007, p. 12, grifo e tradução nossa) acrescenta ainda outros correlatos: "[...] o espaço hodológico em Lewin e Sartre, o espaço do corpo próprio em Husserl ou Merleau-Ponty, o espaço do Dasein em Heidegger, o espaço tímico em Binswanger, o Umwelt em Uexküll, o entorno comportamental em Koffka etc". As variações de uma mesma compreensão do espaço como dinâmico se multiplicam ao longo do século $X X$ e atravessam diversas matrizes do pensamento.

"O verdadeiro espaço é o espaço motor" é a última afirmação do matemático Henri Poincaré (1995, p. 61) no inesperado e rigoroso percurso de um ensaio que não cessa de reportar a noção de espaço a uma experiência eminentemente corporal, motora. De fato, mesmo ali, desde uma condição onde tenderíamos a esperar o espaço abordado como objetivo, Poincaré - à maneira de uma descrição avant la lettre da cinesfera labaniana em suas propriedades - diz do sistema de coordenadas, "[...] 
ao qual relacionamos naturalmente todos os objetos exteriores" que é "[...] um sistema de eixos que está invariavelmente ligado ao nosso corpo e que transportamos por toda parte conosco" (POINCARÉ, 1995 , p. 61). O movimento e o transporte do corpo, portanto, fundam experiencialmente o espaço:

Localizar um objeto quer dizer simplesmente representar os movimentos que seria preciso fazer para alcançá-lo; explico-me: não se trata de representar os próprios movimentos no espaço, mas unicamente de representar as sensações musculares que acompanham esses movimentos, as quais não supõem a preexistência da noção de espaço. (Ibidem, p. 53).

O sentido das palavras de Poincaré, datadas de 1905, praticamente se repeteemLaban, queassiminicia seu curto texto Le sens spatial de l'homme motorique:

A divisão do espaço em diferentes dimensões, direções e posicionamentos se baseia na experiência do movimento corporal. O sentido espacial é de origem dinâmica. Para a frente, à esquerda, à direita são expressões que designam movimentos em relação ao centro do nosso corpo. A ideia de dimensionalidade supõe um centro de onde as seis direções se irradiam. (LABAN, 2003, p. 43, tradução nossa).

A evidência deste espaço esculturado, tratado e experienciado por quem move (e por quem vê mover) como uma arquitetura de linhas e fluxos é assim anunciada por Laban: "O espaço vazio não existe. Ao contrário, o espaço é a superabundância de movimentos simultâneos". (LABAN, 1976, p. 3, tradução nossa).

Assim afirmado, o espaço é tomado como nem objetivo nem subjetivo, mas fundado a partir de uma dimensão corporal; o corpo é matriz do espaço do mundo, tornado simultânea e paradoxalmente interior e exterior. O espaço é afirmado não como algo a ser ocupado ou espectado, mas construído e secretado pelo corpo em movimento, que inscreve infindáveis linhas em gestos e percursos. É compreendido, enfim, como uma matéria cuja modulação se faz desde o corpo.
Figura 1 - Fotograma de Serpentine Dances, de Auguste e Louis Lumière (1899).

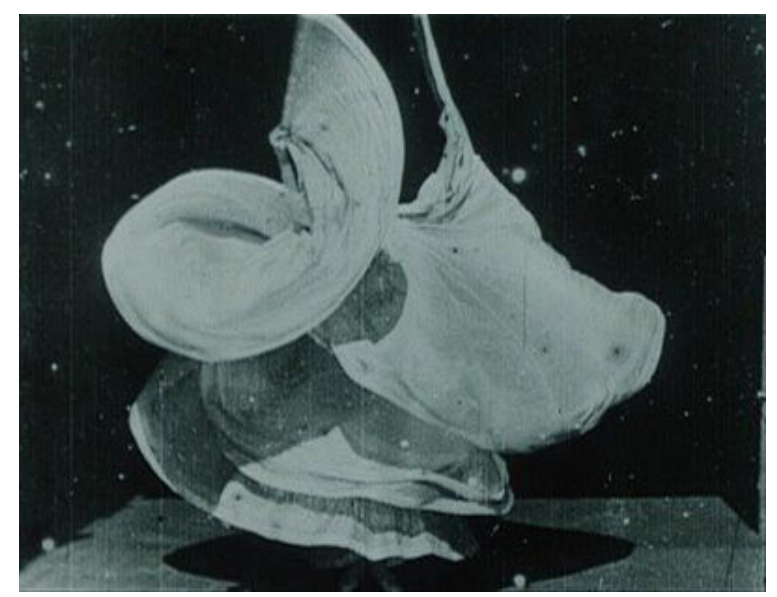

Fonte: Disponível em: https://liquidability.wordpress. com/2012/03/11/hello-world/.

Figura 2 - Imagem produzida a partir da Escala A, de Laban.

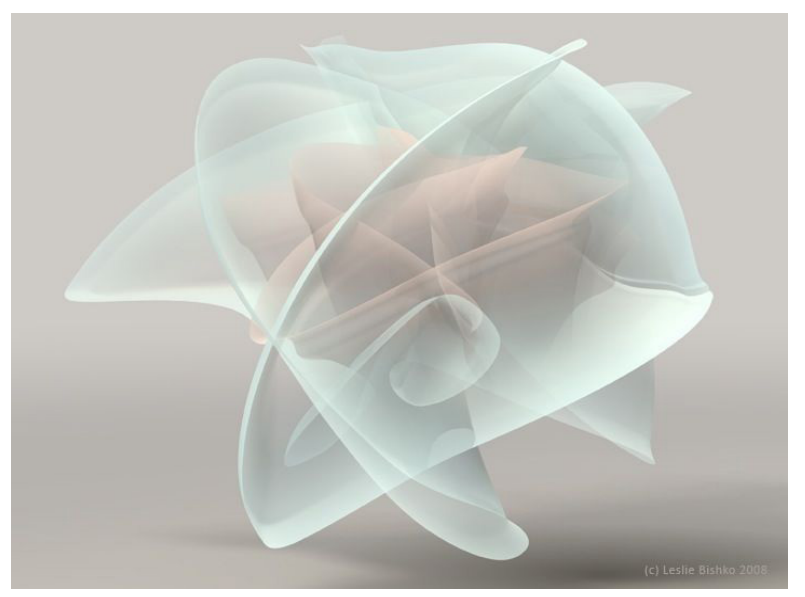

Fonte: Leslie Bishko. Disponível em: https://labanbc.files.wordpress.com/2008/07/a_scale_traceform_72dpi.jpg.

A linha

Há aqueles que olham o mundo e veem linhas: "[...] se nos movemos, descrevemos sempre várias linhas no espaço", diz Laban (LABAN, 2003, p. 43, tradução nossa). "Se desloco minha mão, não importa o que eu faça, traço uma linha no espaço", concorda o encenador Robert Wilson (WILSON, 1998, p. 4). Entre as muitas linhas que se poderiam distinguir, 
o antropólogo Tim Ingold (2007) - em seu Lines: a brief history - privilegia dois tipos numa assumidamente insatisfatória taxonomia: entre fios (threads) e traços (traces), vê se materializarem muitos - não todos - fazeres humanos e não humanos. Fios são, define, filamentos de algum tipo, categoria em que se listariam a corda de um violino, a teia da aranha ou a ponte suspensa; traços categorizam as marcas deixadas por um movimento continuado sobre uma superfície, aditivas ou redutivas conforme somem ou subtraiam dela alguma matéria: assim, a tinta sobre o papel faz marcas aditivas, enquanto o cinzel sobre a madeira as faz redutivas. Nem aditiva nem redutiva é a célebre line made by walking (linha feita pelo caminhar), no entanto, que Richard Long deixa na relva, em 1967, evocada pelo próprio Ingold como exemplo da incompletude tranquila de seu esforço classificatório. A propósito das linhas da geometria abstrata, escreveu Ingold: "[...] infinitamente fina, escrita sobre um plano que é transparente e sem substância, ela é [...] um tipo de 'fantasma' das linhas": ghostly line (linha fantasmática). (INGOLD, 2007, p. 47, tradução nossa).

Figura 3 - A Line Made by Walking, de Richard Long (1967).

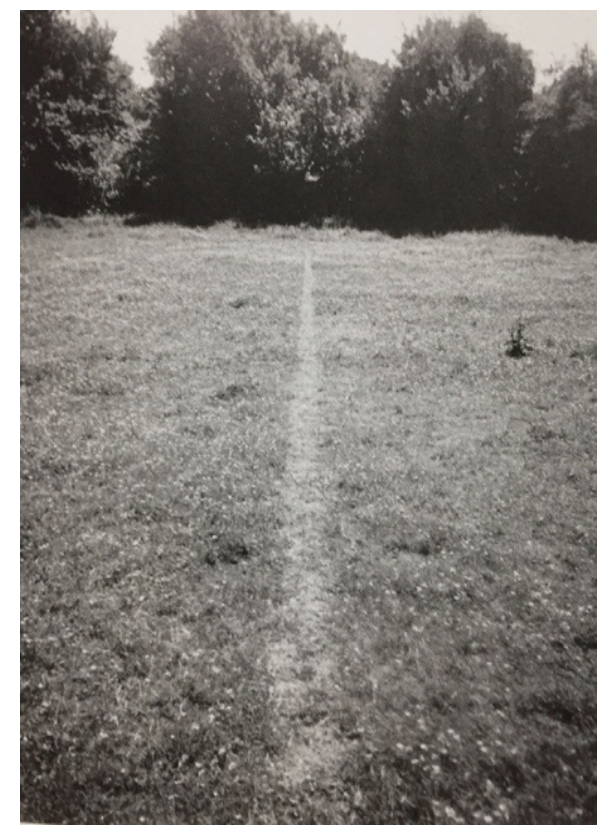

Fonte: Disponível em: https://www.tate.org.uk/art/ artworks/long-a-line-made-by-walking-p07149.
Mas como se referir àquelas linhas que os gestos desenham no ar, evocadas por Laban e Robert Wilson? Numa rara referência à dança, Ingold apenas diz que, diferentemente da caligrafia, as linhas traçadas em seus movimentos usualmente não deixam traço ${ }^{4}$; ele sequer as cita entre aquelas que "não se encaixam" em sua classificação. Contudo, diferentemente das linhas da geometria abstrata, as linhas traçadas no ar são materiais, ainda que talvez demasiado invisíveis, fugazes e transitivas - pensemos nos artifícios de Étienne-Jules Marey para estudar os movimentos do ar por meio dos registros de volutas da fumaça ${ }^{5}$.

Figura 4 - Reconstituição da máquina de fumaça de É.-J. Marey (1974).

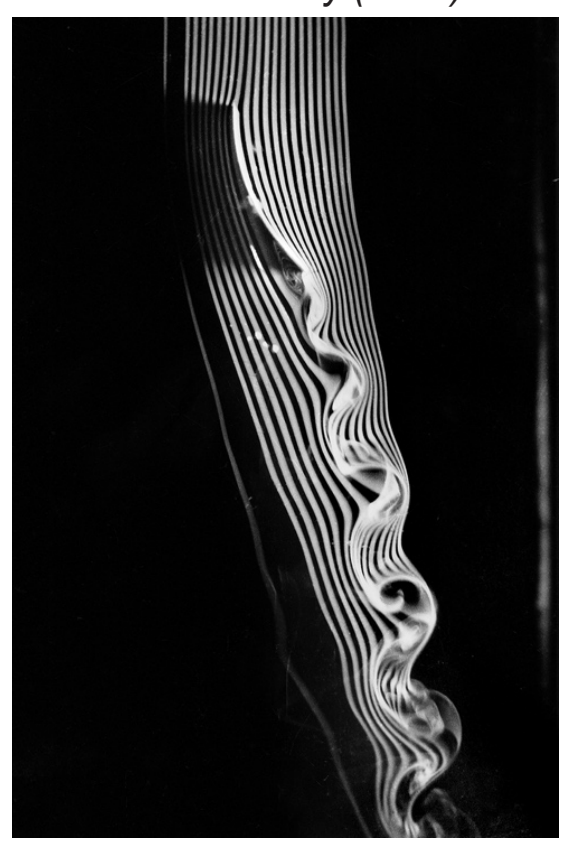

Fonte: Disponível em: https://www.atile.fr/architecture/scenographies/etienne-jules-marey-musee-dorsay-75.php.

O que, sobretudo desde Marey, toda uma variedade de meios gráficos faz é precisamente multiplicar artifícios no sentido de dar a ver tais linhas-

4 Ingold diz precisamente: "E, claro, os gestos do calígrafo usualmente (mas não sempre) deixam traço, enquanto os do dançarino geralmente não (ainda que às vezes deixem)". (INGOLD, 2007, p. 134)

5 Consultar DIDI-HUBERMAN; MANNONI (2004).

Caldas // Linhas Serpentinas: Notas sobre uma abordagem labaniana do espaço Revista Cena, Porto Alegre, no 32 p. 58-72 set./dez. 2020 Disponível em: http://seer.ufrgs.br/cena 
-traços transitivas feitas de ar. Aqui, todo um outro capítulo poderia se abrir, tematizando fazeres ora científicos - como os do próprio Marey -, ora artísticos (cenotécnicos, gráficos, fotográficos, filmográficos, digitais) - como, num certo sentido, os fazeres de Loïe Fuller em suas danças serpentinas, do próprio Laban em suas muitas ilustrações, e também, apenas para listar alguns exemplos frequentes, de Marcel Duchamp (em seu Nu descendant un escalier, de 1912), de Man Ray e do futurismo, passando pelo curta-metragem Pas de deux (1968), de Norman McLaren, chegando às recentes produções desenvolvidas com múltiplas tecnologias digitais.

Figura 5 - Marche de l'homme, de É.-J. Marey
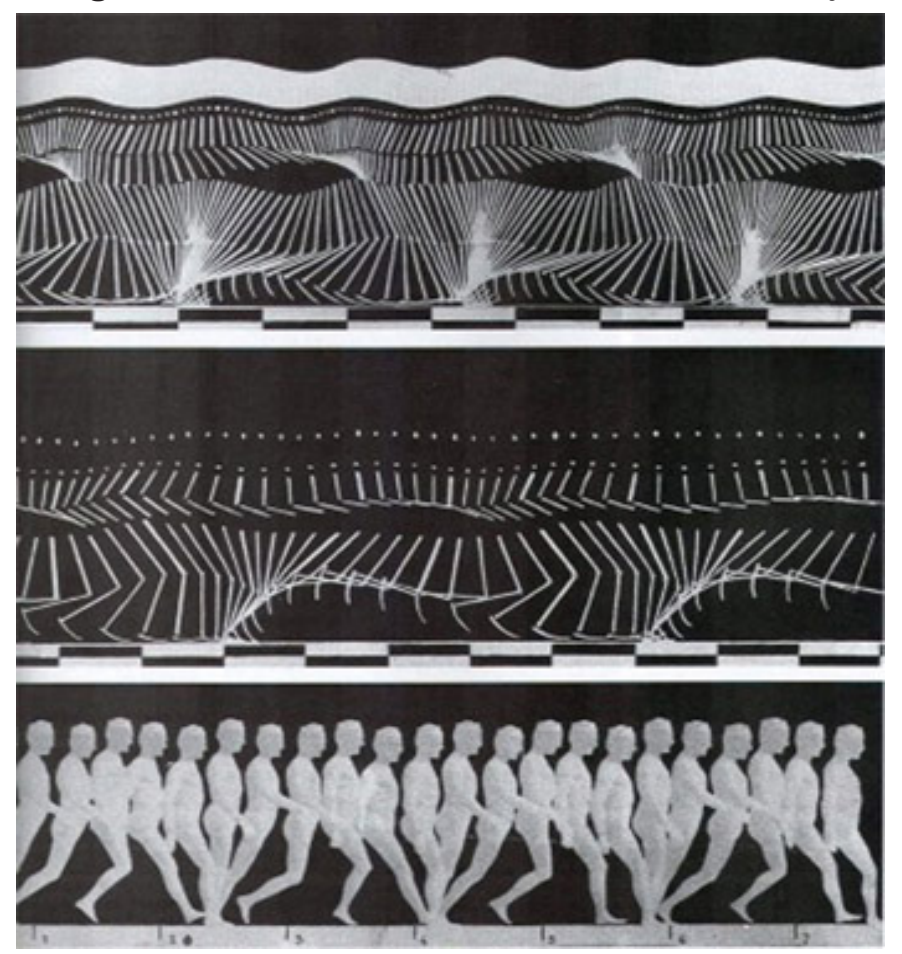

Fonte: Disponível em: http://www.all-art.org/history424-1.html.
Figuras 6 e 7 - (esquerda) Marcel Duchamp, foto de Man Ray (ca. 1920). (direita) Light-Trap for Henry Moore n. 2, de Bruce Nauman (1967).
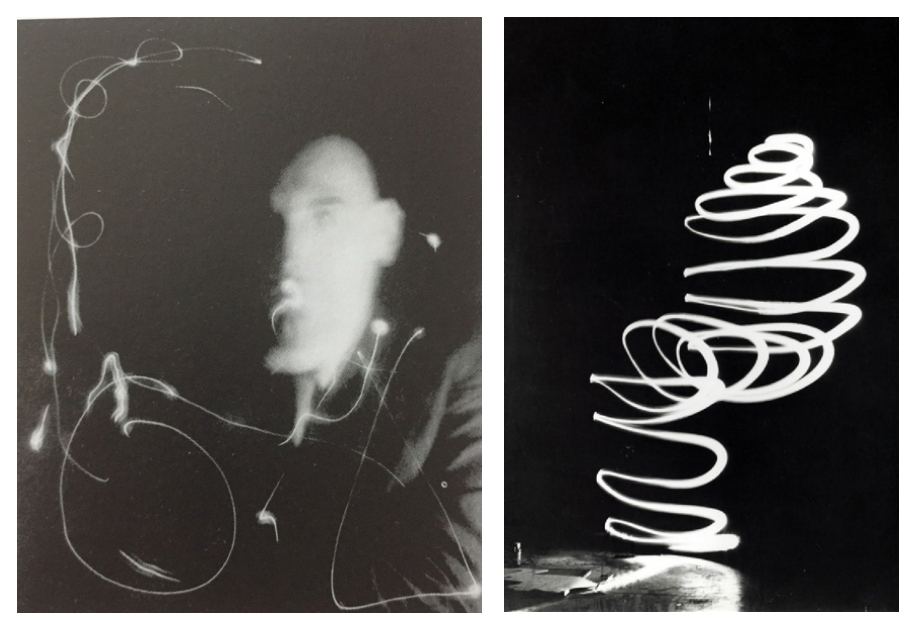

Fontes: Disponíveis em: https://i.pinimg.com/originals/fa/00/99/fa0099ef9af55b597fe3e43c2404be-

9fjpg; e https://www.researchgate.net/figure/ Bruce-Nauman-American-b-1941-Light-Trap-for-Henry-Moore-No-1-1967_fig2_305396758.

Ao tratar da obra de Marey, Georges Didi-Huberman diz:

Como é o mundo, é uma questão de metafísico que Marey e Man Ray vão, ambos, deliberadamente ignorar; o que desejavam saber, no entanto, é como dança o mundo. No entanto, era necessário, para responder a este tipo de pergunta, inventar novos modos de inscrição do movimento e do tempo, em resumo [citando Walter Benjamin] "integrar na própria imagem o que é fluido e cambiante". (DIDI-HUBERMAN; MANNONI, 2004, p. 314-315, grifos dos autores, acréscimo e tradução nossa).

Acerca do impacto das imagens de Marey, diz ainda:

Mesmo a noção de escultura será revirada a partir deste pensamento cronofotográfico do movimento ou do fluxo, quando Bruce Nauman partirá de um traço - um tipo de dança gráfica efetuada por um ponto luminoso - para refletir sobre as possibilidades de sua construção espacial (DI- 
DI-HUBERMAN; MANNONI, 2004, p. 314-

315, grifos dos autores, tradução nossa).

Figura 8 - William Forsythe em Improvisation technologies (1999); exemplo de linha-traço transitiva com a operação descair curvas (dropping curves).
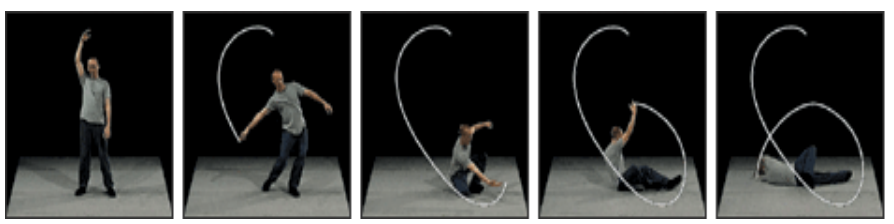

Fonte: Stills do CD-rom Improvisation Technologies (FORSYTHE, 2012).

Os traços de Ray e Nauman não são outros senão as linhas-traços transitivas, relacionáveis aos traços-formas (trace-forms) de Laban, e que também predominam nas Improvisation technologies ${ }^{6}$, do coreógrafo William Forsythe, junto ali ao que poderíamos reconhecer como linhas-fios (no corpo) e como linhas-fantasmáticas: daí que, em seu princípio (simultaneamente seu começo e seu prolegômeno), Forsythe fale sobre imaginar linhas (imagining lines):

O primeiro exemplo que dei - como construir uma linha - era ponto-ponto: linha. Há uma linha entre os dedos [linha-fantasmática], e é possível deixar esta linha ficar no espaço. É possível pegá-la outra vez e movê-la em qualquer direção. Agora, uma outra maneira de construir uma linha é simplesmente usar uma parte do corpo. E esta parte do corpo - digamos, entre este ponto [punho] e este ponto [cotovelo] no meu corpo - é uma linha [-fio]. (FORSYTHE, 2012, p. 46, acréscimos nossos, tradução nossa).

Para coreógrafos, portanto, amiúde toda uma outra geometria dinâmica pode se instaurar desde os corpos - tomados como linhas-fios -, suas imaginações - tomadas como linhas-fantasmáticas, ou sobre-

6 Publicado na forma de um CD-rom, reúne um repertório de "operações" coreográficas desenvolvidas no âmbito dos processos criativos do Frankfurt Ballet e o Solo, de William Forsythe, gravado em 1995 e originalmente concebido para o vídeo Evidentia, de Sylvie Guillem. tudo seus movimentos - tomados como linhas-traços transitivas ${ }^{7}$. Linhas são a matéria (visível ou invisível) fundamental destas outras geometrias próprias a certos fazeres coreográficos. Donde, ao produzir linhas retas, curvas, espiraladas, angulosas, ziguezagueantes ou tremidas, "[...] o bailarino é [...] também o geômetra imediato de seu corpo em movimento" (DIDI-HUBERMAN, 2006, p. 37, tradução nossa).

Figuras 9, 10 e 11 - Nas Improvisation Technologies (1999), exemplos do que poderíamos reconhecer como linha-fio (o antebraço), linha-fantasmática (imaginada de mão a mão) e linha-traço transitiva (produzida, aí, a partir de um movimento iniciado no chão).
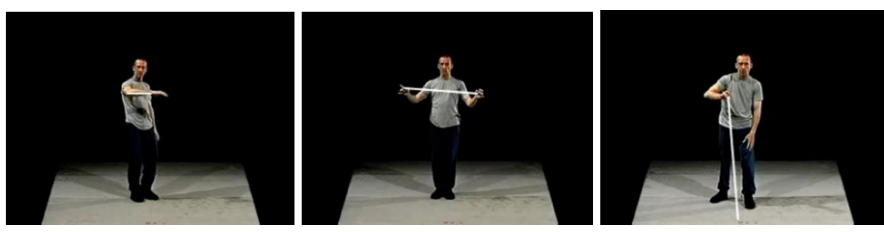

Fonte: Stills do CD-rom Improvisation Technologies (FORSYTHE, 2012).

A geometria

$\mathrm{Na}$ dança, todo o corpo - e na nova dança, cada dedo - desenha linhas de expressões precisas. [...] Todo o corpo do dançarino, até a ponta de seus dedos, constitui a todo instante uma composição ininterrupta de linhas. (KANDINSKY, 2005, p. 100, grifo do autor, tradução nossa).

O espaço do corpo - que José Gil (2004, p. 48) adjetiva como paradoxal pois diferente do espaço objetivo e no entanto inseparável dele -, Laban

70 que estamos designando como linhas-traços transitivas - repetimos - são condição para o que Laban se refere como traços-formas (trace-forms). Como afirma Carol-Lynne Moore (2009, p. 131), "[...] linhas de movimento podem ser conceitualizadas com relação à direção, à localização na cinesfera e às sensações cinestésicas associadas. Entretanto, à medida que um movimento progride, várias linhas são traçadas no espaço ao redor do corpo. Estas linhas complexas criam uma impressão de forma. Laban se refere a estas formas do movimento como "traços-formas". 
o concebeu segundo linhas de uma geometria que se define "performativamente" por traços de movimento referenciados em figuras, afinal, cristalinas. Mas, antes delas, sua primeira figura é uma esfera. Esta esfera que é de movimento - a cinesfera - se define a partir de todo o espaço potencialmente tangível pelo corpo estacionário, e assemelha-se a "[...] uma versão em 3D do Homem Vitruviano, de Leonardo" (SUTIL, 2013, p. 177, tradução nossa).

Leonardo da Vinci não escreveu ele mesmo sua teoria do movimento: suas formulações aparecem, no entanto, reconhecidas no Codex Huygens, manuscrito datado de aproximadamente 1530 , atribuído a um autor com ela familiarizado ${ }^{8}$. Nos desenhos ali esboçados, enquanto linhas retas parecem querer reencontrar as proporções vitruvianas do corpo, linhas circulares descrevem os percursos do movimento no espaço. Leonardo "[...] percebeu na forma do círculo o correto padrão para o movimento do corpo humano que dava a ele uma 'segunda forma', que se tornava visível no movimento circular em torno de seu próprio centro e no dos membros em torno de suas várias articulações" (PANOFSKY apud MOORE, 2009, 68, tradução nossa). PontiIhadas nos desenhos, as linhas-traços transitivas circulares davam a ver os percursos das "[...] figuras realizando os estágios sucessivos de um único mesmo movimento" (PANOFSKY apud MOORE, 2009,68 , tradução nossa). No seu O pensamento e o movente, no capítulo que dedica à vida e à obra de Félix Ravaisson, Henri Bergson faz referência a tais linhas serpentinas em Leonardo da Vinci:

Há, no Tratado de pintura de Leonardo da Vinci, uma página que M. Ravaisson gostava de citar. É aquela na qual nos é dito que o ser vivo se caracteriza pela linha

8 As pranchas que integram o Codex Huygens estão numa exposição online mantida pelo The Morgan $L i-$ brary \& Museum. Consultar: http://www.themorgan.org/ collection/Codex-Huygens. A autoria do Codex é atribuída ao artista italiano Carlo Urbino (ca. 1510/1520 - depois de 1585). Seu nome deve-se a seu proprietário, Constantijn Huygens (1628-1697), que o adquiriu em 1690, acreditando ser de autoria do próprio Leonardo. ondulada ou serpentina, que cada ser tem sua maneira própria de serpentear, e que o propósito da arte é tornar esse serpenteamento individual. "O segredo da arte de desenhar é descobrir em cada objeto a maneira particular pela qual se transmite através de toda a sua extensão, como uma vaga central que se desdobra em vagas superficiais, uma certa linha flexuosa que é como seu eixo gerador". Esta linha, aliás, pode não ser nenhuma das linhas visíveis da figura. Não está mais aqui do que ali, mas dá a chave de tudo ${ }^{\text {. }}$ (BERGSON, 2006, p. 270-271, grifos e tradução nossas).

Em Laban, o espaço do corpo supõe, afinal, um tal serpenteio: ele é cinesférico pois o movimento do grego, kinesis - tende a sugerir uma esfera - do grego, sphaira -, "[...] conforme a natureza rotatória do movimento de nossas articulações" (MALETIC, 1987, p. 59, tradução nossa). Para além dos limites da cinesfera, o espaço é intangível (ou total ou global ou, mesmo, do desejo). Evidentemente, caberá sobretudo aos pontos distais do corpo alcançar-lhe os limites. Sem se deslocar, o corpo se estende, torce, curva e inclina de modo a arquitetar uma geometria que é feita de todo o espaço modulável entre o próximo e o distante, entre tensões menores ou maiores.

A performance generativa deste espaço é já o manifesto de um projeto coreográfico: um corpo que performa sua cinesfera em gestos vizinhos ao seu centro e outro que o faz arriscando-se no quase desequilíbrio de seu limite cinesférico insinuam regimes

9 A referência utilizada por Bergson está no verbete des$\sin$ (desenho), do Dictionnaire de pédagogie et d'instruction primaire, publicado em 1882 e assinado por Félix Ravaisson. Na página 680, lemos: "A forma, disse Michelangelo, dever ser 'serpentina' (serpentinata); e Leonardo da Vinci: 'Observe, para desenhar, a maneira de serpentear de cada coisa (il modo di serpeggiare)'. Dito de outra maneira, o segredo da arte de desenhar é descobrir em cada objeto a maneira particular com que atravessa toda a sua extensão, como uma onda central que se desdobra em ondas superficiais, certa linha flexuosa que é como seu eixo gerador". In: BUISSON, Ferdinand. Dictionnaire de pédagogie et d'instruction primaire, Partie 1, Tome 1. Paris: Librarie Hachette et Cie, 1882. Disponível em: <https://gallica.bnf.fr/ark:/12148/bpt6k24232h/f684.item. textelmage.zoom>. Acesso em 19 out 2020. 
estéticos/estésicos distintos: "[...] o dançarino se move não apenas de lugar para lugar, mas também de estado para estado", lê-se numa anotação de Laban (apud MOORE, 2009, p. 109, tradução nossa).

Para além do perfeito equilíbrio tensional da figura esférica, Laban nela inscreveu três dos chamados sólidos platônicos: o octaedro (e seus 6 vértices), o icosaedro (e seus 12 vértices) e o cubo (e seus 8 vértices) tornaram-se especialmente relevantes para o mapeamento volumétrico do espaço do dançarino na cinesfera. Associados o corpo e as três figuras cristalinas numa mesma compreensão cartográfica - ou seja, justapostos octaedro e icosaedro num "[...] cubo imaginário dentro de nossa esfera pessoal de movimento" (LABAN, 1990, p. 88), em torno de um mesmo centro que é também o do corpo -, estabelecem-se aqueles 27 pontos que um dançarino usual e pragmaticamente frequenta ao projetar-se no espaço ${ }^{10}$.

Figura 12 - Os 27 pontos e as principais linhas direcionais no espaço cúbico.

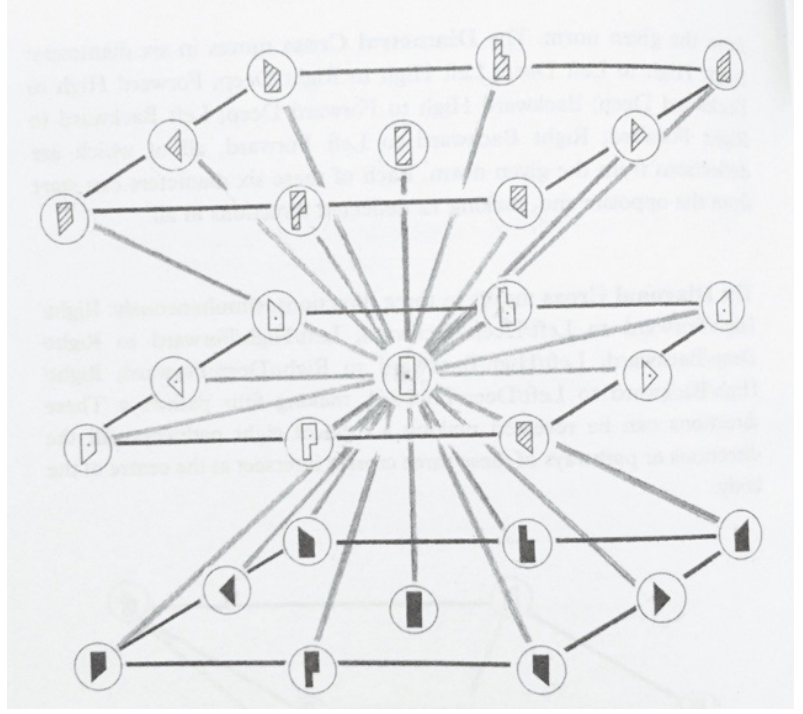

Fonte: Laban (2003, p. 89).

10 Assim, sobre este espaço cúbico, uma definição a partir das figuras cristalinas utilizadas por Laban seria: os 27 pontos somam os 6 vértices do octaedro, os 12 do icosaedro, os 8 do cubo e o centro do corpo (ao centro): $6+8+12+1=27$; ou ainda: uma descrição de matriz balética seria: o corpo ao centro e as 8 direções em torno dele (numeradas de 1 a 8 a cada $45^{\circ}$ a partir da frente), considerados - direções e corpo $(8+1)$ - nos 3 níveis espaciais (baixo, médio e alto): $9 \times 3=27$.
Marque-se que a geometria proposta por Laban trata não de extensidades, mas de intensidades; ela é inseparável de uma experiência performativa do espaço e se empenha pela compreensão de uma lógica de forças.

Laban reconhece que a geometria do espaço e as geografias cristalinas que utiliza para orientar o movimento podem parecer frias e intelectuais, em contraste com a experiência sensória do fluxo do movimento. No entanto, acredita que o dançarino pode aprender a "compreender o movimento vivo numa plasticidade geométrica”, unindo uma compreensão intelectual do espaço com uma sensibilidade corporal para o movimento expressivo. Laban sugere que "com a crescente compreensão de nosso sentido cinestésico podemos reconhecer que nossos nervos têm a capacidade de uma genuína percepção das qualidades espaciais" (MOORE, 2009, p. 121, tradução nossa).

Daí que o octaedro, o icosaedro ou o cubo sejam formas geométricas instituídas a partir de uma compreensão dinâmica em que o trânsito dos corpos se dá por linhas de força e pelas sensações a ela associadas: é desde o movimento que se funda esta arquitetura móvel em que uma eucinética sempre subjaz a uma corêutica.

\section{A explosão}

A geometria do espaço emerge do corpo em movimento. "A ideia é cristalina; o fato, fluido", disse o escritor Stewart Brand (apud INGOLD, 2011, p. 212, tradução nossa). O peso é o elemento fundamental; é sobretudo a sua modulação que definirá aquilo que Laban nomeou esforço; e é a partir da análise desta modulação no corpo terreno - do jogo entre a anatomia e a gravidade - que tenta reconhecer uma lógica tácita e, enfim, formular as chamadas harmonias espaciais. Marque-se, no entanto, que tais formas corêuticas se pretendem apenas ponto de partida: a palavra repetidamente empregada para descrever, por exemplo, os desdobramentos forsythianos das matrizes espaciais de Laban é 
explosão ${ }^{11}$. Point of departure: the dancer's space (Ponto de partida: o espaço do dançarino), de Valerie Preston-Dunlop (2008), cuja primeira edição data de 1984, é uma obra que multiplica imagens de octaedros, icosaedros e cubos, de linhas que os percorrem e atravessam descrevendo as escalas e anéis das harmonias espaciais propostas por Laban. Ao introduzir seus termos, Preston-Dunlop declara: "[...] há regras a serem observadas, quebradas, expandidas e abandonadas" (PRESTON-DUNLOP, 2008 , p. 1, tradução nossa). Assim como nas harmonias musicais, cujas configurações frequentemente se expandem "[...] como se estivessem aparentemente ausentes", as harmonias espaciais - advoga - também devem ser usadas criativamente: "Não são baseadas num conjunto de regras para serem adotadas. Ao contrário, as formas mostram novas possibilidades de relação espacial. Seu uso é um "ponto de partida" para o mundo de aventura criativa no espaço da dança" (PRESTON-DUNLOP, 2008, p. 1, tradução nossa). Assim é que, em 2008, passadas mais de duas décadas de sua primeira edição, e já publicizados os procedimentos forsythianos e as Improvisation technologies, a obra é reeditada e acrescida de um breve segundo texto de Agradecimentos (Acknowledgements) em que lemos:

A maneira com que William Forsythe explodiu os conceitos corêuticos de Laban em seu método de improvisação corêutica é agora bem conhecido; quando trabalho criativamente com o material neste livro, eu tenho os métodos de Forsythe por detrás do meu espírito e diante do meu corpo. (PRESTON-DUNLOP, 2008, p. iii, tradução nossa).

11 A palavra é usada repetidas vezes, por exemplo, num texto referencial sobre o coreógrafo, escrito por Patricia Baudoin e Heidi Gilpin (2000): Proliferation and perfect disorder: William Forsythe and the architecture of disappearance.
As linhas se multiplicam consideravelmente já nos circuitos harmônicos reconhecidos por Laban ${ }^{12}$. Mas, para além deles, há todo um espaço pleno das virtualidades de movimento, rede que acolhe qualquer linha - distante ou próxima, ínfima ou extrema, previsível ou imprevisível, harmônica ou aberrante. A propósito de uma das operações ${ }^{13}$ das Improvisation technologies - inscriptive modes (modos de inscrição) - Forsythe diz:

Poderia estabelecer uma linha ao marcar alguns pequenos pontos ou entre dois outros pontos. Poderia provavelmente manchá-la, deslizá-la, batê-la, golpeá-la, chutá-la. Uma linha ou um ponto estão ali no espaço e o modo com que você os estabelece, ou com que os manifesta, depende realmente de você. É muito importante que esta parte do processo permaneça extremamente lúdica e extremamente imaginativa. Não se limite apenas ao desenho estrito de linhas, como se você estivesse desenhando com uma faca ou uma caneta. Você tem que usar a atividade do seu corpo e sua imaginação sobre como as linhas podem se formar. $E$ como você pode manifestar estas coisas com seu corpo e não apenas como se você estivesse segurando um instrumento de escrita. Isto é muito, muito importante. (FORSYTHE, 2012, p. 58-59, tradução nossa).

120 referido livro de Preston-Dunlop - Point of departure - ocupa-se, ao longo de suas 126 páginas, apenas de descrever não menos que 22 tipos de circuito, entre escalas e anéis.

13 O que Forsythe se refere como "operação" é uma pequena proposição coreográfica. Cada uma abre um infinito de possibilidades exploratórias. Há operações que inventam movimentos; há as que reinventam (modificando um ou mais parâmetros quaisquer de um dado material). Linhas serão estendidas, transportadas, seguidas, desviadas, prolongadas, correspondidas, deslizadas, acercadas, percorridas, evitadas, contornadas. Como diz Forsythe ao iniciar a explanação sobre ângulo e superfície (angle and surface): "O número de abordagens para linhas que se estendem do seu corpo é provavelmente tão rico quanto for a sua imaginação. $E$ os modos de abordar estas linhas são provavelmente quantas você mesmo puder pensar". (FORSYTHE, 2012, p. 50, tradução nossa). 
De fato, as imagens que se multiplicam usualmente como representações gráficas dos circuitos labanianos dão a ver longas e continuadas linhas evoluindo por entre os limites da cinesfera. A razão de que assim sejam nos parece dupla: de um lado, as linhas extremas deixam experienciar mais própria e intensamente as forças; de outro, deixam ver os traços-formas ${ }^{14}$ mais distintamente, pela grandeza que assumem na esculturação do espaço. Há, portanto, um duplo desejo didático de clareza, que se repete aliás, pelas mesmas razões, nos contextos de sala de aula em que a geometria do espaço é tematizada. É frequente desenharmos aquelas longas e continuadas linhas com nossa habitual mão direita, antes que - destros - arrisquemos a mão esquerda e então sigamos com iniciações outras quaisquer, não necessariamente distais. Num certo sentido, o mesmo também se passa nas imagens em movimento de muitas das operações descritas nas próprias Improvisation technologies: Forsythe recorrentemente dispõe de sua mão direita para produzir, manipular e transformar o espaço de uma geometria invisível agora tornada visível pelos grafismos computacionais. Daí que sua insistência em dizer que "[...] não é preciso que seja assim"15 torne-se especialmente importante.

Point of departure (Ponto de partida) poderia ser a correta expressão a indicar a apropriação feita por Forsythe das referências labanianas. Suas Improvisation technologies resultam de um extenso e cumulativo processo de pesquisa coreográfica e de seguidas fases de desenvolvimento como recurso de tecnologia gráfica interativa. Os sucessivos anos de processos criativos fizeram acumular séries de operações. As Improvisation technologies, desenvolvidas como um tutorial - um recurso de aproximação

14 Segundo Laban (1976, p. 5), "o movimento é, por assim dizer, uma arquitetura viva - viva no sentido de mudar disposições e também de mudar coesões. Esta arquitetura é criada pelos movimentos humanos e é composta por caminhos que traçam configurações no espaço que podemos chamar de 'traços-formas'”. diz: "[...] este é um dos nossos lemas, literalmente: 'isto não tem que ser assim'. (FORSYTHE; SULCAS, vídeo, 2016).
15 Numa conversa com a crítica Roslyn Sulcas, Forsythe

de novos bailarinos ao contexto criativo do hoje extinto Frankfurt Ballet, companhia dirigida por Forsythe de 1984 a 2004 - inventaria dezenas de operações; o CD-rom [...] foi também chamado de uma "escola de dança" (dance school; FORSYTHE, 2012, p. 16).

Mais do que um inventário, no entanto, elas informam sobre duas infinitudes: aquela que imediatamente se reconhece naquilo que se opera (pois que as configurações de movimento que procedem de qualquer operação são inesgotáveis), e aqueloutra - mais fundamental artística e pedagogicamente: a infinitude de qualquer processo que se coloque a criação de operações como estratégia poética. De outra maneira: diante das Improvisation technologies, para além da produção de algo desde as operações já ali inventariadas, importa notar a declaração intrínseca de que há sempre infinitas operações a inventar. Donde a bailarina Natalie Thomas, uma professora com certificação nas Improvisation technologies, possa dizer: "Os sistemas das 'Tecnologias' de Forsythe criam novos sistemas, este é o ponto. Portanto, eu inventei minha própria maneira de ensinar, minha versão do que aprendi com Bill [William Forsythe] e da minha experiência desde que o deixei" (STERN, 2014, p. 69, acréscimo e tradução nossa).

Da leitura dos Choreutics, de Laban, Forsythe pode estabelecer os fundamentos de um processo investigativo que fez do espaço a matéria de sua poética corporal. Em suas proposições, aquilo que Laban havia erigido como referência matricial de toda uma geometria do espaço se vê multiplicada: a cinesfera - espaço tangível do corpo sem deslocamento - que, em Laban, se reportava ao centro único do corpo, reaparece em Forsythe virtualmente em cada um dos múltiplos pontos quaisquer do corpo: joelhos, cotovelos, nariz, escápula, o que se queira, passam a ser o centro de improváveis investidas na geometria espacial.

O modelo de Laban se adequa ao vocabulário de movimento do balé particularmente bem, uma vez que emprega um ponto central no corpo como elemento estruturante. Mas, e se o movimento não emanar do centro do corpo? E se a origem do movimento for uma
Caldas // Linhas Serpentinas: Notas sobre uma abordagem labaniana do espaço Revista Cena, Porto Alegre, n' 32 p. 58-72 set./dez. 2020 Disponível em: http://seer.ufrgs.br/cena 
linha inteira ou um plano, e não simplesmente um ponto? A Corêutica inspira estas questões. Embora reconhecendo as promessas do sistema de Laban, William Forsythe o explode deslocando seu centro infinitamente pelo corpo. Forsythe considera toda uma série de cinesferas, por assim dizer; cada uma é inteiramente colapsável e expansível. Uma infinidade de divisões de eixos rotacionais emergentes pode ter como seu centro o calcanhar do pé direito, a orelha esquerda, o cotovelo direito, ou todo um membro, por exemplo. No desmantelamento e na suspensão do modelo de Laban, qualquer ponto ou linha no corpo ou no espaço pode ser tornar o centro cinesférico de um dado movimento. Um modelo similar pode ser engendrado em qualquer ponto fora ou dentro da cinesfera; e a cinesfera é permeada com um infinito número de pontos de origem que podem aparecer simultaneamente em múltiplos pontos do corpo (BAUDOIN; GILPIN, 2000, documento eletrônico, tradução nossa).

Cinesferas multiplicadas atomizam o corpo e nele promovem uma experiência cinestésica complexa: já agora o corpo em movimento é multifocado, multitemporalizado, em contraponto consigo mesmo. Uma vez introduzido às teorias labanianas do espaço, Forsythe as torna operadoras de um virtualmente infinito processo de problematização, tensionamento e, afinal, desdobramento das matrizes baléticas em que ele mesmo se formou e que nunca recusou. A partir delas, as Improvisation technologies ocupam-se sobretudo - desde uma compreensão do espaço a partir de linhas - com novas estratégias para a invenção coreográfica.

\section{A operação (um documento)}

Curiosamente, as referências a Laban não aparecem na versão final e publicizada do CD-rom lançado comercialmente em 1999 com o título Improvisation technologies: a tool for the analytical dance eye. As limitações de armazenagem de sua mídia impuseram uma seleção a partir de um material bastante mais abrangente e numeroso. A versão do tutorial utilizada efetivamente pelo Frankfurt Ballet ocupava um disco rígido, e passou a ser disponibilizada ape- nas por meio de consulta presencial ao Deutsches Tanzarchiv (Arquivo Alemão de Dança), em Colônia. Datada de 1994, em seus créditos lemos: Improvisation technologies: digital dance training equipment. Nesta versão, instalada num Power Macintosh 7300/166 - outrora um poderoso desktop da Apple, descontinuado no final dos anos 1990 -, é possível ainda hoje navegar por operações inéditas, fragmentos de ensaios e performances da obra Self Meant to Govern, de 1994, incorporada no ano seguinte ao espetáculo Eidos: Telos. Sua interface permite alternar, conforme se deseje, entre as imagens registradas a partir de quatro enquadramentos diferentes da obra, que também serve para exemplificar - tanto com imagens dos ensaios de criação quanto da cena - as operações descritas e explicadas por Forsythe.

Figura 13 - Printscreen do protótipo do Improvisation technologies.

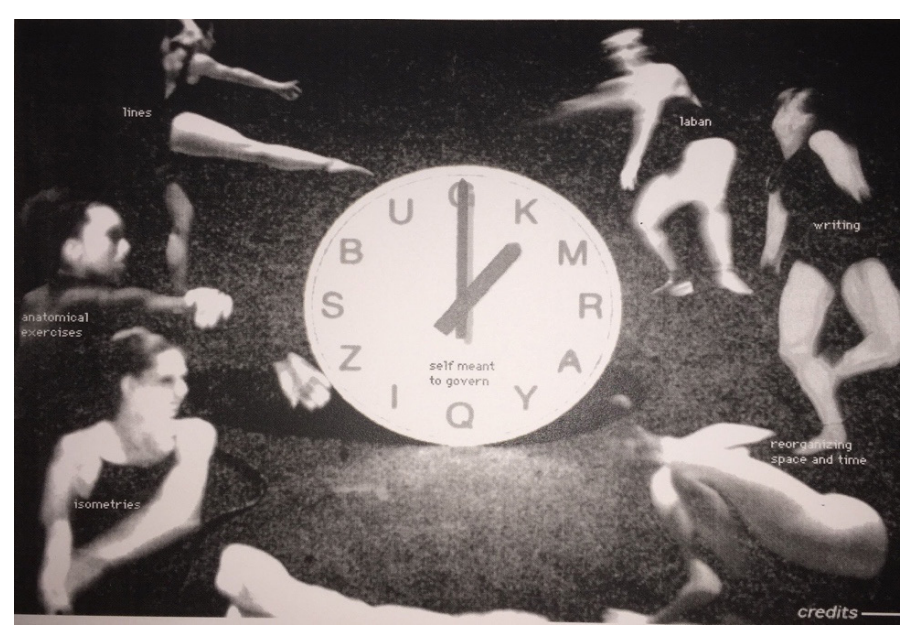

Fonte: Acervo pessoal do autor. 
Figura 14 - Printscreen do protótipo do Improvisation technologies.

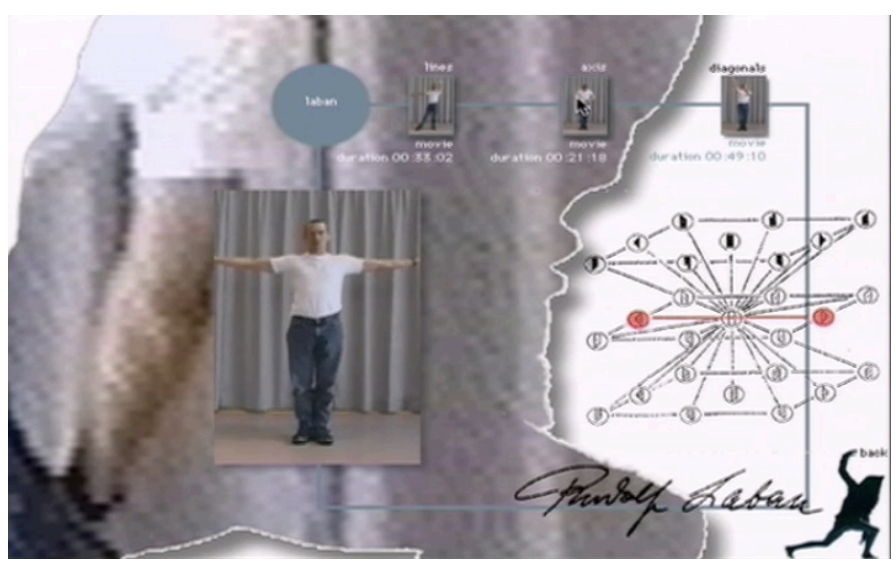

Fonte: Acervo pessoal do autor.

Ao centro de sua tela de abertura, vemos a imagem de um dos relógios que se espalhavam na cena de Self Meant to Govern, e cujas letras (em lugar de números) davam referências aos bailarinos quanto a que operações recorrer. Ao seu redor, imagens de bailarinos sobre os quais se escrevem os links de acesso. Se percorridos no sentido horário - sugestão que a própria imagem do relógio reforça - assim se listariam: laban, writing, reorganizing space and time, isometries, anatomical exercises, lines. Nas primeiras palavras do link laban, Forsythe declara sua filiação: "A noção destas linhas vem de ideias propostas por Rudolf Laban, que foi um teórico da dança do início do século XX". Depois de descrever o modelo de laban (laban model) segundo o cubo imaginário de 27 pontos definidos pelas linhas dimensionais, diametrais e diagonais a partir do centro, Forsythe acrescenta: "Mas este modelo pode ser do tamanho que você quiser que seja; ele pode ser pequeno assim [do tamanho da mão], se você precisar que seja; você pode colocá-lo onde você quiser no seu corpo".

Como partes da seção que tem o título geral laban, as cinco explanações seguintes atestam outros desdobramentos - pequenas explosões - da matriz labaniana. (Dado o seu completo ineditismo, são por nós aqui integralmente transcritas e traduzidas,

assim como acrescidas de indicações espaciais. $)^{16}$. No tópico modelo de laban (laban model), no item orientação de partes internas do corpo (orientation of inner body parts), Forsythe multiplica as cinesferas e enfatiza a multiplicação de iniciações corporais (especialmente as não distais):

Imagine que seu corpo fosse um tipo de série infinita de pontos e linhas, e que cada um destes pontos pudesse - em essência - mover em torno deste modelo que acabei de explicar. Então, tomaria este ponto - por exemplo - a ponta do meu dedo - e o moveria para vários pontos do modelo de Laban; você verá que, na verdade, começo a estabelecer áreas que você conhece do balé. Por exemplo, bum [abaixo - à direita à frente], bum [abaixo - à esquerda - atrás], bum [acima - à frente - à direita], bum [à frente], bum [atrás] etc, etc, coisas assim. Você já é familiarizado com as direções em que estes pontos existem no modelo de Laban; mas o que você usualmente faz é orientar o fim das suas extremidades na direção destes pontos. Muito raramente você considera orientar, por exemplo, um ponto interno como seu cotovelo na direção destes pontos, ou algo como seu joelho. Isso começaria a produzir uma relação diferente com o mesmo modelo que você usa todo dia. Mas, neste caso, você prioriza, ou dá importância, a todos os pontos e todas as linhas em seu corpo. (FORSYTHE, 1994, tradução nossa).

No tópico modelo de laban (laban model), no item cinesfera (kinesphere), ele sugere que, independentemente da iniciação, o movimento não precisa necessariamente se dar no limite da cinesfera labaniana (ou das múltiplas cinesferas que se pode estabelecer):

Há várias maneiras de se mover em torno do modelo com pontos; a maneira em que se move em torno do modelo com as extremidades é na periferia; e se você esticar completamente suas extremidades, alongar suas pernas e seus braços, você perceberá que está criando círculos; e esta esfera de movimento é chamada de sua cinesfe-

16 Nossa visita ao Deutsches Tanzarchiv, em Colônia, na Alemanha, foi feita no final de novembro de 2014. 
ra. Este é o limite dos seus próprios movimentos; e quando você está se movendo na cinesfera, você está movendo na - ou ao longo da - periferia, a parte externa do modelo. Há também a possibilidade, no entanto, de se mover dentro do modelo, mas isso requer um tipo diferente de corpo, um corpo flexível; o corpo se dobra e se orienta da mesma maneira, sem os membros esticados. (FORSYTHE, 1994, tradução nossa).

No tópico geral (in general), no item movimento não linear (unlinear movement), Forsythe usa o modelo para referenciar os desvios do próprio modelo, quanto ao que ele sugere de direcionamento, dimensão e forma do movimento:

Há mais de um modo de orientar-se no modelo de Laban e mais de uma maneira de abordar o exterior do amplo modelo de Laban. É possível valer-se de formas mórficas ${ }^{17}$ ou formas indefinidas ou ações menores e orientá-las para direções muito distintas no modelo; poderia escolher a diagonal alta como um ponto; poderia usar um movimento que não fosse tão claramente linear e que ainda assim se dirige para cima na diagonal; poderia usar uma simples espiral revertida e movê-la na direção da diagonal direita baixa; assim se compreende que o modelo não induz apenas formas geométricas duras. (FORSYTHE, 1994, tradução nossa).

No tópico geral (in general), no item tempos e ritmos diferentes (different times and rates), ele sugere uma multitemporalização do corpo:

Seu corpo, quando está no modelo, muito frequentemente orienta-se para mais de um ponto ao mesmo tempo. E, nesta técnica, a ideia é manter seu corpo orientando-se para mais de um ponto ao mesmo tempo e em mais de um tempo ao mesmo tempo. Isto significa que - em vez de mudar [de posição], mudar, mudar, as coisas chegam em ritmos diferentes e diferentes partes do seu corpo orientam-se para diferentes pontos em ritmos diferentes. (FORSYTHE, 1994, tradução nossa).

17 Aquelas que têm uma forma específica já conhecida.
E, finalmente, no tópico geral (in general), no item flexibilidade do modelo (flexibility of the model), propõe que as linhas ou formas possam não ser tão evidentes ou declaradas:

Quando você está escrevendo, quando está inscrevendo as linhas - de novo - elas não são sempre desenhadas como linhas suaves, mas às vezes é possível fazer linhas frágeis, fracas, irregulares, e para fazer isso com diferentes partes do corpo... vamos pegar uma pequena forma de triângulo, por exemplo, agora, e movê-la ao longo de uma linha [Forsythe desenha uma linha descendo verticalmente num pequeno ziguezague feito com o ombro direito até o chão]. Você também poder fazer linhas muito fracas, por exemplo... [ele desenha um pequena linha com o pé direito, saindo um pouco do chão para a frente]; nem todas as linhas são fortes; você pode pegar uma linha daqui, digamos, desta diagonal e expandi-la e colapsá-la; as coisas não precisam ser - como poderia dizer? - tão sólidas. (FORSYTHE, 1994, tradução nossa).

Depois de, pelo menos, cinco anos percorrendo seminários e simpósios, a versão das Improvisation technologies destinada à comercialização se apresenta como um tutorial divido em quatro seções - cada uma das quais nuança certos aspectos improvisacionais/composicionais -, acrescidas de um solo no qual o próprio William Forsythe se esforça por comprimir em seus menos de sete minutos de duração o quanto pôde das operações que inventaria ${ }^{18}$. Inquieto, seu movimento serpenteia incontáveis linhas. Sem nenhuma preocupação de claramente descrevê-las e identificá-las, ou de explicitar uma operação qualquer em jogo, vemos de fato seu corpo multiespacializado e multitemporalizado materializar toda a problematização da matriz clássica que o marca, a partir de um uso desdobrado e explodido das formulações espaciais labanianas. O Solo se inicia, aliás, remetendo-nos literalmente

18Acerca do Solo, Forsythe disse: "Eu estava basicamente tentando compactar 25 anos de dança em 7 minutos; então, nele pode-se ver que eu tentei comprimir todos os capítulos de teoria naqueles sete minutos" (FORSYTHE, 2012, p. 18). 
a uma posição clássica ${ }^{19}$ : o close no movimento dos pés exibe-os frequentando e desdobrando a $5^{a}$ posição do balé, como a reiterar um procedimento que atravessa todo seu modus composicional. Uma frase do escritor Witold Gombrowicz bem Ihe serviria de epígrafe: "Mas não até que eu me abandonei à minha dança solo - só então meus pensamentos adquiriram carne e se tornaram ação". (GOMBCROWICZ, 2000, p. 143, tradução nossa).

\section{Referências}

BAUDOIN, Patricia; GILPIN, Heidi. Proliferation and perfect disorder: William Forsythe and the architecture of disappearance. Disponível em: http://www. frankfurt-ballett.de/artic1.html. Acesso em: 24 jan. 2000. [website descontinuado; arquivo pessoal]

BERGSON, Henri. O pensamento e o movente. São Paulo: Martins Fontes, 2006.

BESSE, Jean-Marc. L'élan du paysage. Premières notes sur la danse et l'écriture. Les carnets du paysage, n. 13-14, 2007, numéro spécial "Comme une danse", pp. 11-19.

CERTEAU, Michel de. A invenção do cotidiano: artes do fazer. 3a ed. Petrópolis: Editora Vozes, 1998.

DIDI-HUBERMAN, Georges. Le danseur des solitudes. Paris: Les Éditions de Minuit, 2006.

DIDI-HUBERMAN, Georges; MANNONI, Laurent. Mouvements de l'air: Étienne-Jules Marey, photographe des fluides. Paris: Gallimard, 2004.
FORSYTHE, William. Improvisation technologies: a tool for the analytical dance eye. Karlsruhe: ZKM/Zentrum für Kunst und Medientechnologie, 2012.

FORSYTHE, William. Improvisation technologies: digital dance training equipment. Colônia: Deutsches Tanzarchiv Köln, 1994. HD.

FORSYTHE, William; SULCAS, Roslyn. Forsythe lectures / Roslyn Sulcas. Disponível em: https://www. youtube.com/watch? $v=M b e 4$ VavLuLI\&t=685s. Acesso em: 03 maio 2020.

GIL, José. Movimento total: o corpo e a dança. São Paulo: lluminuras, 2004.

GOMBROWICZ, Witold. Ferdydurke. New Haven: Yale University Press, 2000.

INGOLD, Tim. Lines: a brief history. Londres, Nova York: Routledge: 2007.

Being alive: essays on movement, knowledge and description. Londres, Nova York: Routledge, 2011.

KANDINSKY, Vassily. Point and line to plane. Nova York: Dover Publications, 1979 [Edição brasileira: Ponto e linha sobre plano. São Paulo: Martins Fontes, 2005].

LABAN. Rudolf. The language of movement. A guidebook to choreutics. Boston: Macdonald and Evans Ltd., 1976.

1990.

Dança educativa moderna. São Paulo: Ícone, Espace dynamique. Bruxelas: Contredanse, 2003.

19 From a classical position (A partir de uma posição clássica) é o título de uma de suas obras - um duo realizado para vídeo em que improvisam o próprio Forsythe e a bailarina Dana Caspersen. 
MALETIC, Vera. Body - space - expression: the development of Rudolf Laban's movement and dance concepts. Berlim, Nova York, Amsterdã: Mouton de Gruyter, 1987.

MOORE, Carol-Lynne. The harmonic structure of movement, music, and dance according to Rudolf Laban: an examination of his unpublished writings and drawings. Lewiston: The Edwin Mellen Press, 2009.

POINCARÉ, Henri. O valor da ciência. Rio de Janeiro: Contraponto, 1995.

PRESTON-DUNLOP, Valerie. Point of departure: the dancer's space. Londres: Verve Publishing, 2008.

STERN, Carrie. Bringing William Forsythe's "Improvisation technologies" to a new generation. Disponivel em: https://www.dancewave.org/uploads/Press $\% 20$ Articles/Dancer\%20Magazine\%20Forsythe\%20 Dec\%2009.pdf. Acesso em: 21 jan. 2014. [link descontinuado; arquivo pessoal]

SUTIL, Nicolas Salazar. Rudolf Laban and topological movement: a videographic analysis. Space and Culture, v. 16, n. 2, p. 173-193, 2013.

WILSON, Robert. Entrevista. Programa do espetáculo Time Rocker. Rio de Janeiro: Fundação Theatro Municipal do Rio de Janeiro, 1998.

Recebido: 10/06/2020

Aceito: 06/08/2020

Aprovado para publicação: 29/11/2020
Este é um artigo de acesso aberto distribuído sob os termos de uma Licença Creative Commons Atribuição 4.0 Internacional. Disponível em: <http://creative commons.org/licenses/by/4.0>.

This is an open-access article distributed under the terms of the Creative Commons Attribution License 4.0 International. Available at: <http://creative commons.org/licenses/by/4.0>.

Ce texte en libre accès est placé sous licence Creative Commons Attribution 4.0 International. Disponible sur: <http://creativecommons.org/licenses/by/4.0>.

(n)

